\title{
A Study on Chinese Network Catchwords in 2018 From the Perspective of Memetics
}

\author{
LIN Li \\ Leshan Normal University, Sichuan, China
}

\begin{abstract}
With the advancement of information technology and in the current development of the network society, the emerging network language, driven by strong language memes, continually derives and spreads. Based on memetics, the paper analyzes the memes phenomenon of Chinese network catchwords in 2018 and that it can be categorized into three forms. And it further explores the reasons for the popularity of network catchwords: simplicity, vividness, and defamiliarization.
\end{abstract}

Keywords: meme, memetics, Chinese network catchwords in 2018, forms, reasons

\section{Introduction}

With the development of technology, interpersonal communication based on network has become increasingly common and frequent. Network language is the language created in and applied to network, which includes Chinese and English letters or characters, punctuations, signs, pictures, or the combination of them. It came into being from 1990s for netizens, with the innovation and advancement of network technology, wanted to improve their chatting efficiency or achieve their specific needs, such as humor or amusement. And now it has become an indispensable part in people's life. Network catchwords refer to language forms which are widely popular among netizens in a particular historical period. New network catchwords appear every year and they are analyzed and studied from the perspective of social linguistics or psychology in the academic circle. And this paper attempts to explore the forms of memes in Chinese network catchwords in 2018 and the reasons for its popularity with the theory of memetics.

\section{Memetic Theory}

\section{Memetics and Meme}

Memetics, based on Darwin's theory of evolution by natural selection, is a new theory to explain universal relationship between things and evolution rules of culture with inheritance diachronically and synchronically. The core term of memetic theory is "meme", which is coined by Dawkins in his best-selling book The Selfish Gene in 1976. In Chapter 11 of the book, he firstly proposes the concept of meme as the following:

...I think that a new kind of replicator has recently emerged on this very planet. It is staring us in the face. It is still in its infancy; still rifting clumsily about in its primeval soup, but already it is achieving evolutionary change at a rate that

LIN Li, master, lecturer, School of Foreign Languages, Leshan Normal University, Sichuan, China. 
leaves the old gene panting far behind. The new soup is the soup of human culture. We need a name for the new replicator, a noun that conveys the idea of a unit of cultural transmission, or a unit of imitation. "Mimeme" comes from a suitable Greek root, but I want a monosyllable that sounds a bit like "gene". I hope my classicist friends will forgive me if I abbreviate mimeme to meme. If it is any consolation, it could alternatively be thought of as being related to "memory", or to the French word meme. It should be pronounced to rhyme with "cream". (Dawkins, 1976, p. 192)

Meme is a new concept; it exists long before we realize its existence. When you speak catchwords, follow a fashion trend, or sing a popular song, you have definitely encountered a meme. Dawkins (1976, p. 192) demonstrated it as follows:

a name for the new replicator, a noun that conveys the idea of a unit of cultural transmission, or a unit of imitation. Examples of memes are tunes, ideas, catch-phrases, clothes fashions, ways of making pots or of building arches. Just as genes propagate themselves in the meme pool by leading from body to body via sperm or eggs, so memes propagate themselves in the meme pool by leaping from brain to brain via a process which, in the broad sense, can be called imitation. If a scientist hears, or reads about, a good idea, he passes it on to his colleagues and students. He mentions it in his articles and his lectures. If the idea catches on, it can be said to propagate itself, spreading from brain to brain.

According to the viewpoint of Dawkins, meme is a unit of cultural transmission, it can be language, customs, ideas, or social behaviors which are continuously replicated and transmitted. People's ideas can obtain evolution by the way analogous to evolution of living creature.

Since the publication of Dawkins' The Selfish Gene in 1976, memetics has attracted a range of scholars from various disciplines. Another treatment of memes is the book The Meme Machine by the psychologist Susan Blackmore in 1999. In her book, "meme" is depicted from a more comprehensive and systematic manner than ever before. In her point of view, memes are involved in everything in human society, the evolution of the culture, the origin of language, the spread of religion, and the development of internet as well. Blackmore (1999) argued that any information, in a broad sense, can be called memes as long as it can be copied by means of imitation.

In Chinese linguistic field, the pioneer who sets foot in memetics is Gui Shichun (2002) in the preface of the book Language and Culture (as cited in Gu \& Lu, 2002). He gives a very brief introduction to the term "meme" and suggests that memetics be employed to linguistic study. Since then, following his perception, some scholars in China have engaged in memetic research to enrich the language study in a systematic way. Professor He Ziran and He Xuelin (2003) employed the theory to analyze language, discusses replication of meme in language, and especially analyzes social usage of Chinese. He (2016) analyzed what pragmatic functions language meme and its variant can display in public discourse communication.

\section{Main Concepts About Meme}

Meme and memeplexes. Meme does not always work alone. According to Dawkins (1976), memes are ideas, habits, skills, stories, or any other kind of behavior or information that is copied from person to person by imitation. They range from single words and simple actions to the vast memeplexes of science are religion, politics, and finance (Blackmore, 1999). Just as a set of genes can work together, a group of memes can also work together and get transferred together to reinforce each other. Such a group of mutually-assisting memes can be called a memeplex, abbreviated from "co-adapted meme complexes". Like memes, memeplexes spread as long as there is some reason for them to be copied. On the one hand, good combination of memes can favor survival of memeplexes, on the other hand, memeplexes can enhance survival of memes.

Strong meme and weak meme. Like genes, memes endure and copy themselves with variations, which are 
naturally selected, and thereby evolve. Like genes, they are "selfish", or rather, their function is the promotion of their own survival. Therefore, during the process of natural selection, those memes which can effectively propagate themselves, occupy and sustain a relatively long time in people's memories are called strong memes, while those memes which are easily to be forgotten are called weak memes. One point needing to emphasize is that not all strong memes or weak memes always remain the same. Strong memes may become weak memes as times goes by, likewise, weak memes may turn into strong memes. This is all because selection and evolution of memes is a dynamic process. Strong memes and weak memes are relative in a time of period.

Characteristics of memes. Memes spread through society. As a kind of replicator, successful memes obtain the following characteristics listed by Dawkins (1976):

1. Longevity: The longer a replicator persists, the more copies it can make.

2. Fecundity: A meme must make as many copies of itself as quickly as possible. It is much more important than the characteristic of longevity. The faster the rate of replicating is, the more the replicator will spread.

3. Copying-fidelity: Fidelity is the precision with which a replicator copies itself. Generally speaking, the more faithful the copy is, the more successful the meme is. Dawkins regards this characteristic as the most important one for meme's survival.

$\mathrm{Xu}$ Shenghuan (2005) concluded the features of memes as following:

1. Ability of replicating: Meme can be copied by means of imitation.

2. Long continuity: Meme can be spread from one generation to another.

3. Inheritance: Meme must maintain its certain natures and characteristics in the process of propagation; it cannot be totally irrelevant with its initial pattern though some change or variation occurs.

4. Variation: The process of propagation is a process of natural selection, only the fittest can obtain survival. Therefore, meme varies according to the environment so as to better adapt to the new one.

From the viewpoint of these scholars, it is concluded that meme must be copied accurately, more copies should be made, the copies should last a long time, and meme should make variation according to the environment.

Stages of meme replication. According to Heylighen (1998), a meme must pass through four subsequent stages when it is replicated from one generation to another. The first stage is assimilation; the meme must be assimilated, understood, and accepted by a host through infection. The second stage is retention; the meme must be kept a period in host's memory. The next stage is expression; it means the meme should be expressed by the individual in language, behavior, or another form that can be perceived by others. The last stage is transmission; an expression needs a physical carrier or medium to transmit the expression in order to reach another individual.

\section{Memetic Study of Chinese Network Catchwords in 2018}

\section{Forms of Memes in Chinese Network Catchwords in 2018}

A network catchword must be qualified with attention value and memory value so as to arouse people's attention and get people to make use of it. The memetic approach is such a device to express people's feelings, emotions, or thoughts for the transmission feature of meme has a naturally instinct association with the popularity of network catchwords. “咬文嚼字” (yao wen jiao zi), a Chinese magazine about usage of Chinese characters, released the top 10 Chinese network catchwords, respectively, “命运共同体” (a community of shared future), 
“锦鲤” (koi fish), “店小二” (waiter or bartender), “教科书式” (textbook-like), “官宣” (an official announcement), “确认过眼神” (look sb. in the eye or get confirmation), “退群” (withdraw from a group), “佛 系” (Buddha-like), “巨婴” (giant baby), and “杜精” (people who argue for the sake of arguing). The forms of memes in network catchwords can be divided into three main types, that is, new words as memes, old words with new semantic meanings as memes, and old words with new usage as memes.

\section{New words as memes.}

(1) 命运共同体 (a community of shared future). It was firstly put forward in the 18th National Congress of the Communist Party of China in 2012. The original phrase, proposed by Chinese President Xi Jinping, is a community of shared future for mankind, which means the international community is increasing becoming a community of shared future with the advancement of society and development of economy for no country can be an isolated island in the face of the complex situation and global problems of the world economy. “命运共同体” (a community of shared future) is a new concept of human society repeatedly emphasized by the Chinese Government.

Economic globalization has prompted people to reflect on the traditional concept of national interests. The instantaneous global transmission mechanism has transformed the planet inhabited by human beings into a "global village"; the high integration of national interests makes different countries a link in the chain of common interests. Any problem in any link may lead to the disruption of the global interest chain. For example, when food security problems arise in a country, hungry people will flock to other countries on a large scale. And the progress of transportation has made it possible for the flow of refugee tide, while the progress of humanism has made the refusal of refugees face great moral pressure. The Internet connects all countries together in an unprecedented way and if a country launches cyber-attacks at any point in the world, seemingly silent, but the economic and social losses to the target countries may be no less than a war. The glacier melting, precipitation imbalance, and sea level rise caused by climate change will not only bring disaster to small island countries, but also do great harm to dozens of coastal developed cities in the world. The shortage of resources and energy is related to the continuation of human civilization, and environmental pollution leads to the frequent occurrence of strange diseases and cross-border epidemics. Faced with growing global problems, no country can be alone. If any country wants to develop itself, it must let others develop; if it wants to be safe, it must let others live safely; if it wants to live well, it must let others live well. Under such circumstance, people now have a new understanding of the common interests. Since human beings are already in the "global village", citizens of all countries are also citizens of the earth, and the interests of the whole world are also their own interests. When a country takes measures to benefit the interests of the whole world, it also serves its own interests.

In this context, the phrase “命运共同体” (a community of shared future) now has, both economically and politically, become a network catchword in Chinese, and even a global hot word.

(2) 官宣 (an official announcement). “官宣” literally means an official announcement, originated from the official announcement of their marriage from two Chinese stars (actor William Feng and actress Zhao Liying). On October 16, 2018, the two Chinese stars posted “官宣” (an official announcement) on Weibo, followed by a red heart. Below the Weibo were wedding photos and marriage certificates, announcing their marriage. A few days later, “官宣” (an official announcement) appeared in both traditional and new media, all of which were announced by someone or an organization. Then, it quickly became popular. The word “官宣” (an official 
announcement) derives from "official website" and "official micro". Its "official" refers to the owner of a right. "Official" originally refers to the government, such as "official personage" and "official news". If unofficial acts of an individual or an institution are claimed as "official", it is to emphasize their authority and reliability. And now when any news accompanied by “官宣” (an official announcement) is announced, it is to express the meaning of publicity.

Modern people are exposed to so much news every day, both true and fake, and the meaning of “官宣” is "an official announcement", the connotation of which is authority and reliability, so the word is widely spread, quickly becoming popular, even the NBA player Nick Young used it in his Weibo.

(3) 杜精 (people who argue for the sake of arguing). The Chinese new word “杜精” refers to people who argue for the sake of arguing. The counterpart of this word in English is probably "contrarian". This group of people always wants to have the last word.

The word is made of two Chinese characters “杜”, which means figuratively "imperious” or “argument-liking” and “精”, one meaning of which refers to a person who is very good at something. So, the meaning of word is quite obvious. There are always such people, who like to get their sense of superiority by suppressing other people's opinions. For example, if a girl keeps working out every day and shares her workout records on WeChat Moment. “杜精” (people who argue for the sake of arguing) always comment like this “It is ugly for girls to have big muscles. Are not you afraid of hurting yourself while doing the power training?" or "Over-exercise would be 100 percent detrimental to your health. Just stop it".

“杜精” (people who argue for the sake of arguing) can be found everywhere online, constantly stirring up trouble. They just argue for the sake of arguing, no matter when or where. The word gets wide popularity because it, briefly and precisely, describes the characteristics of that type of people and people's disgust with that kind of behavior.

(4) 佛系 (Buddha-like). The catchword “佛系” means a state of mind, which focuses on the process of things happening with the mentality of "do one's best and leave the rest to God's will" and does not pay attention to the results. The word originated in a Japanese magazine in 2014, which introduced "Buddha-like men". In December 2017, the phrase "Buddha-like youngsters" was posted all over WeChat Moment and the Internet. As a cultural phenomenon, “佛系” refers to a lifestyle and an attitude toward life: Live in your own way. To be more frank, it means it is fine to have or not to have; or it is just fine to win or to lose; or to ask for noting, strive for nothing. The word derives a series of words, such as “佛系父母” (Buddha-like parents), “佛系粉丝” (Buddha-like fans), “佛系恋爱” (Buddha-like love), and “佛系饮食” (Buddha-like diet).

Faced with great pressure from all sides, people would rather be Buddha-like, live in their own way. This is exactly the reason why this word is becoming so popular.

\section{Old words with new semantic meanings as memes.}

(1) 锦鲤 (koi fish). It is the Japanese word for carp, a brightly colored type of freshwater fish commonly used in Asian landscape and design. The koi fish has a powerful and energetic life force, demonstrated by its ability to swim against currents and even travel upstream. During the National Day of 2018, Alipay official micro-blog launched a raffle event, randomly picking a prize winner from the bloggers who had forwarded this micro-blog. The event attracted netizens' forwarding for more than 3,000,000 times. On October 7, Alipay announced the results of the lottery, the lucky prize winner, getting the "globally free gift packs", was called 
"Chinese koi fish". After the event, “锦鲤” (koi fish) became popular immediately, and the Internet set off a wave of forwarding images of koi fish. “锦鲤” (koi fish) became the symbol of good luck. Later, as the heat grew, “锦鲤” (koi fish) began to refer generally to people who had good luck in small probability events. And the popularity of koi fish and the generalization of its symbolic meaning imply people's yearning for a better life.

(2) 店小二 (waiter or bartender). “店小二” originally refers to waiters or bartenders who are responsible of the reception of customers in teahouse, restaurant, or hotel in the old days. Their enthusiastic attitude and thoughtful service is an important aspect of a good experience a teahouse, a restaurant, or a hotel brings to customers. Now, the meaning and the context of this word has changed greatly. For instance, the main leaders of Zhejiang Province in China have advocated that government sectors, leading cadres should serve enterprises and grass-roots units well as “店小二” (waiter or bartender). From the example, it can be seen that the word “店小二” (waiter or bartender) has gradually evolved into a new meaning, referring to government sectors and leading cadres who promote economic development and provide thoughtful services to enterprises. This year, the main leaders of Shanghai in China also emphasized that the government should strive to do a good job as “店小二” (waiter or bartender) and carrying forward the spirit of “店小二” (waiter or bartender) is re-positioning of the roles of government sectors and leading cadres in the social and economic structure and a concrete measure to deepen the reform in the new era. So, the word gets popularity for its wide spreading in mass media and for enterprises, grass-roots units and even ordinary people hope that government sectors and leading cadres can be enthusiastic and thoughtful as “店小二” (waiter or bartender) when dealing with problems involved.

(3) 退群 (withdraw from a group). “群” refers to a group established on Wechat, QQ, or other social platforms for a certain number of people to communicate; and “退群” means to withdraw from the communication group on a social platform. Later, the meaning extended, the scope of use expanded, now the word “退群” also refers to withdrawal from a group (not only on a social platform). After Trump became President, the United States withdrew from many international agreements or organizations, such as the Trans-Pacific Partnership Agreement, the Paris Climate Change Agreement, the Comprehensive Agreement on Iran's Nuclear Issue, the Universal Postal Union, UNESCO, and so on. Trump even threatened that the United States would withdraw from the World Trade Organization. As a result, “退群” (withdraw from a group) has become a high-frequency hot word, widely appearing in news reports.

(4) 巨婴 (giant baby). “巨婴” originally refer to large babies. But in recent years, the term has been used to refer to adults who are mentally stuck in infancy. Such people are absolutely self-centered and extremely selfish. They take other's help and gifts for granted and have no sense of gratitude. They have no sense of rules, no legal concept, and no moral restraint. Once the situation exceeds their expectations, they will lose control of their emotions and behave excessively and irrationally. They protest in a baby-like way, trying to make others or even the surrounding environment yield or give in by crying, shouting, physical conflict, and other extreme methods, so as to achieve their own purpose and thus bring disastrous consequences to the society. This year, "high-speed railway tyrant" and "Chongqing Wanzhou bus crashed into river" and other incidents furtherly increased the heat of “巨婴”. “巨贞” phenomenon have attracted the attention of the whole society.

\section{Old words with new usage as memes.}

(1) 确认过眼神 (look sb. in the eye or get confirmation). “确认过眼神” means to look sb. in the eye or to get confirmation. It firstly appeared in the lyrics of Singapore singer JJ Lin's A Story in Red Cliff: looking her in 
the eye (I know I have met my Miss. Right). Now, the meaning of the catchword is "confirmed" or "screened". This usage was first derived from a micro-blog during Spring Festival "Confirmed, you are Cantonese", attached with a picture of an one-RMB red envelope, which ironically implies Cantonese usually give little gift money during Spring Festival. This micro-blog made the phrase “确认过眼神” (look sb. in the eye or get confirmation) become a catchword immediately, and it frequently appeared in news titles, advertisements, and so on. At the beginning of its popularity, as what the phrase literally means, the context where the phase was used is related to people. However, in the process of subsequent communication and use, the semantic of the catchword has been generalized and gradually extended to refer to things. For example, "Confirmed, I know I have met the right cooker". After further development, the scope and scale of its semantic generalization have been further expanded, and the actual meaning of the phrase has become fuzzier and fuzzier, and sometimes, it is just a discourse marker, such as "confirmed, tell the truth together", "confirmed, do not forget to write a log", and so on. The increasing fuzzy meaning of the word makes it more and more widely used and popular. And the popularity of the phrase reflects people's desire to get the confirmed or screened in the face of a large number of uneven news or even false information.

(2) 教科书式 (textbook-like). In May 2018, someone uploaded a video of Shanghai police enforcing law on the street. When the police investigated and dealt with illegal parking, they asked the driver to show his driver's license. But the drive did not cooperate and his attitude is very brutal. Repeating three times "take out your driver's license" and getting no positive response, they began warning "Police tools will be used, people unconcerned, set aside please". However, the driver still did not cooperate. The police then used tear gas, pulled out the baton, and declared "give up resistance, or force will be used" to control the driver and took him away. The video clip shows both the law enforcement procedures and on-site instructions are impeccable, with textbook-like standardization, which was called by netizens "textbook-like law enforcement". With the popularity of the video, the word “教科书式” (textbook-like) also gradually widely spread. Now, it is used to refer to "normative", "exemplary", "classical", "demonstrative", "perfect", and so on, describing doing something normatively or demonstratively, such as "textbook-like performance", "textbook-like avoidance", and "textbook-like design". Meantime, during the usage of the word, there are also some expressions, such as "textbook-like cheating", "textbook-like set", and "textbook-like trap", which is the ironic usage of the word.

\section{Reasons for the Popularity of Network Catchwords}

Simplicity. Network words must bear the characteristic of simplicity if they want to be popular. The simplicity of language is also called the economic principle of language. Network language, with its extraordinary compactness, can be effective union of several extremely simple and easily understandable morphemes, such as “杜精” (people who argue for the sake of arguing”. The word is made of Chinese character “杜” (figuratively “imperious” or “argument-liking) and “精” (a person who is extremely good at something). The word structure is quite simple, but the meaning is quite obvious. Another example “官宣” (an official announcement). It consists of “官” (authority) and “宣” (announcement). The combination of these two morphemes briefly expresses the meaning-the announcement is official, authoritative, and reliable. These words are quite simple in form and appropriate in meaning, so they are widely spread on the Internet and much loved by netizens. 
Vividness. A word is chosen on the basis of the user's needs, and thus, it should accurately, vividly, and appropriately express the user's utterance intention. Vividness is a prominent feature of Chinese characters. If a word wants to become popular, it must to be easily replicated and highly productive. For example, “佛系” (Buddha-like) vividly expresses a person's state of mind-leave it to be. When the word is used, people always connect it with the image of Buddha. Therefore, there is no doubt that it is highly productive, such words as “佛 系父母” (Buddha-like parents), “佛系恋爱” (Buddha-like love), and “佛系养生” (Buddha-like longevity preservation) come into being later. Take one more word as an example, “店小二” (waiter or bartender). When it is used to refer to government sectors and leading cadres who promote economic development and provide services to enterprises, the image of “店小二” (waiter or bartender) or the attitude he displays一enthusiastic and thoughtful—immediately comes to people's mind. So, it gradually gets wide popularity.

Defamiliarization. The biggest characteristic of network words lies in its defamiliarization. That is to say, the form of it is fresh, sometimes even strange. And this is the main reason for network words to become popular. In the virtual space with greater freedom, people's desire to seek novelty, divergence, and change are magnified. Because of this, people's aesthetic fatigue rises when such words “确定”(confirmed) and “经过鉴定”(identified) are frequently used. Therefore, when the phrase“确认过眼神” (look sb. In the eye or to get confirmation) appears, it immediately causes a sensation, like throwing a huge stone into a calm lake. The phrase, as a language meme, is quite innovative and productive. It can be used in various contexts and expresses the speaker's intention in a concise, humorous, and vivid way.

\section{Conclusion}

Nowadays, the network catchwords have been known to every household, and gradually, become strong memes to be widely spread. Memes, as the carrier of expressing information in network catchwords, have promoted their development. And memes themselves also rely on language itself to get replication and propagation. Network catchwords in various forms greatly enrich network language, and they also display such characteristics of network language as simplicity, vividness, and deformiliarization. From the perspective of memetics, this paper categorizes Chinese network catchwords in 2018 into three forms, interprets the meanings of these memes with specific examples, and analyses the reasons why language memes can be replicated and become popular.

Analyzing network catchwords from the perspective of memetics not only reveals the law of the spread of network language, but also enables us to have a deep understanding of memetics, and even a further understanding of the development and change of human language. 


\section{References}

Blackmore, S. (1999). The meme machine. Oxford: Oxford University Press.

Dawkins, R. (1976). The selfish gene. New York: Oxford University Press.

Gu, J. Z., \& Lu, S. (2002). Language and culture. Shanghai: Shanghai Foreign Language Education Press.

He, Z. R. (2016). Linguistic meme and its variant application. Journal of Xinjiang Normal university (Philosophy and Social Sciences), (3), 133-139.

He, Z. R., \& He X. L. (2003). Memetics and social usage of language. Modern Foreign Languages, 26(2), 200-209.

Heylighen, F. (1998). What makes a meme successful? Selection critieria for cultural evolution. Retrieved 21/01/2018 from https://www.ixueshu.com/document/fc23c1ac954dade8318947a18e7f9386.html

Xu, S. H. (2005). Memetics and the literary intertextuality. Journal of College of Chinese Language and Culture of Jinan University, (1), 59-67. 